IOS Press

\title{
What does an independent official statistical agency mean in practice?
}

\author{
Dennis Trewin \\ Statistical Consultant and Former Australian Statistician, Canberra, Australia \\ E-mail: dennistrewin@grapevine.net.au
}

\begin{abstract}
The paper will discuss the strengths and weaknesses of having an official statistical agency that is independent of Government. It will explain why the strengths far outweigh the weaknesses. There will be some discussion of the institutional place of the official statistical agency and the key principles of enabling legislation. The paper will then discuss what it means in practice to be an independent official statistical agency. What are the main principles and practices that need to be followed? It will finish with a number of scenarios that challenge the realisation of being an independent official statistical agency.
\end{abstract}

Keywords: Official statistics, independence, statistics legislation

\section{Introduction}

The value from having an independent statistical agency is generally accepted but it is debated from time to time. One such occasion was in the UK in 1983 following a decree by the Thatcher Government that only those official statistics required by Government should be funded. This was publicly and vigorously debated, both prior to and after implementation, leading to a White Paper on Open Government which was released in 1993 (see Laux [1]). The Paper included the following statement.

"Official statistics are collected by government to inform debate, decision making and research both within government and by the wider community. They provide an objective perspective of the changes taking place in national life and allow comparisons between periods of time and geographical areas. Open access to official statistics provides the citizen with more than a picture of society. It offers a window on the work and performance of government itself, showing the scale of government activity in every area of public policy and allowing the impact of public policies and actions to be assessed.'

This brief statement reflects the position adopted by many countries. It is also consistent with the UN Fundamental Principles of Official Statistics. However, there are still a number of countries that do not comply with this in practice even though they may be signatories to the Fundamental Principles. They cannot say their official statistical agency is truly independent.

The statistics produced by an independent statistical agency may not always be welcomed by government because they can measure the magnitude of problems or policy failure or by oppositions because they can measure positive progress and policy success. However, they avoid debates on whether the figures have been compiled and presented with a political objective in mind (assuming the statistical agency behaves in an appropriate way).

In this paper, the second section discusses the advantages and disadvantages of an independent statistical agency and the importance of trust. The third section considers the institutional arrangements whereas the fourth section discusses what it means in practice with some illustrations using testing scenarios in the fifth section. Finally, the paper makes some concluding remarks.

\section{Advantages and disadvantages of an independent statistical agency}

The two main advantages of an independent statistical agency are: 
- Official statistics are free of political interference on the statistical methods applied to data collections, and the contents and timing of releases. There is also transparency on the methods used. The statistics are therefore more believable and trusted. This does not mean that Ministers (and other analysts) should not put their own interpretation on the published statistics but the debate should be largely about the meaning of the statistics not how the statistics were compiled.

- National Statistical Offices are more likely to take account of all users, including the community, not just the Government of the day.

In Australia, there has always been strong political support for an independent statistical agency from all sides of politics. The Australian Statistician is indeed one of the best known (and usually highly respected) official position holders in Australia.

Some would argue that there are disadvantages from having an independent official statistical agency. The main arguments are that because of remoteness from Government, products and services may not be as relevant to the current needs of the Government, arguably the most important user. Furthermore, successful requests for funding may be more difficult. However, this depends on the strength of the relationship with Government and influential Departments such as the Ministry of Finance. A constructive relationship does not necessarily compromise independence. I would argue that the most important responsibility of the head of an independent official statistical agency is to nurture those relationships even if it requires saying 'no' on occasions to inappropriate requests.

To be a trusted official statistical agency, you have to behave appropriately. It can take some time to recover from an untoward incident.

What does it mean to be a trusted official statistical agency?

- Trust means statistics are compiled and presented objectively, and there is transparency in the methods used.

- Trust means there is confidence in the quality of statistics - not that they are error free but they are collected and processed professionally and not fudged for expediency.

- Nevertheless, quality is important. If an official statistical agency produces a series of poor quality statistics or a series of unexpected revisions, trust will soon disappear even though it is driven by quality concerns rather than integrity concerns.
- Confidentiality protection is also essential to maintain trust. Businesses/persons will not be willing to complete forms if they don't think they will be protected.

One advantage of trusted official statistics is that they can be used without qualification or question. Incidents will occur from time to time and the most important thing is how they are managed. The worst strategy is to pretend they didn't happen and ignore them. If the incident becomes public, or is likely to become public, the response has to be public as well as quick. Preferably, the public response should be delivered by the chief statistician.

\section{Institutional arrangements}

These will vary by country. It is important to be in a position to have influence. This can be difficult if you are administratively quite separate from other parts of Government. This implies that you need to be administratively aligned with an influential Ministry and/or Minister preferably someone who is a key user of statistics (e.g. Ministry of Finance/Treasury, Ministry of Commerce/Industry) and certainly someone who understands and respects an independent official statistical agency.

Reporting direct to a Minister can work (e.g. Statistics New Zealand) but the Minister must understand the reasons for an independent statistical agency and behave accordingly. This does not mean that the Minister, or others associated with Government, should not make suggestions on improvements in statistical operations, call for greater efficiency or ask the occasional hard question even on statistical methods. After all, they are usually responsible for the majority of funding of official statistics.

It is valuable to be geographically close to the main government users. This is not necessary for production activities but it is important for those involved in the most important user engagement activities.

An independent official statistical agency requires supporting legislation that describes the role of the official statistical agency, how it behaves and its powers.

"To produce reliable and valid statistics it is necessary that Governments provide the legal framework and resources to the statistical systems of their countries to allow statisticians to produce the required statistical information, without interference using the best available methodology and techniques from the best 
suited sources of information." Malaguerra and MacDonald, J of IAOS, 2016.

The Fundamental Principles of Official Statistics provide a framework for statistics legislation. Also, there are many examples of good practice in the public domain such as the web site of the UN Statistics Division. Some of the key elements of statistics legislation would include:

- The functions of the official statistical agency and possibly some elements of their governance (e.g. Advisory Board).

- The main arrangements for guaranteeing independence such as responsibility for the statistical methods; and the timing and content of publications.

- The limitations on Government with respect to national statistics

- The power to collect statistical information; and the power to access administrative information for statistical purposes.

- The confidentiality arrangements including arrangements for researcher access to microdata for statistical purposes and the obligations on those researchers.

- The arrangements for publication and dissemination of statistics.

- Co-ordination of national statistics.

- The desire to conform with international statistical standards. There may possibly be a reference to the Fundamental Principles of Official Statistics given their adoption by the UN General Assembly.

- User consultation arrangements (e.g. Advisory Board).

\section{What does it mean in practice to be an independent statistical agency?}

As mentioned above, there should be a close relationship with the Government and other key users - independence does not mean that you are remote from their needs. After all, the Government is arguably the most important user - a lifeline user in marketing language. It is vital to understand and respond to their statistical needs. They should have a big influence on which collections are conducted as well as their content.

Nevertheless, there should be independence in the determination of statistical methods to be used in the statistical collections, the publication dates and pub- lication contents. A publicly available release calendar can be a good way of avoiding undue pressure to change the timing of release of publications. However, there will be good reasons for changing publication dates from time to time usually because of production delays within the statistical agency. A good practice is to provide a public explanation when release dates have to change to avoid suspicions that they may have changed as a result of Government direction or convenience.

There should be a strong positive relationship with the media. They can be a powerful defender when there are unfair pressures on the statistical agency. More than most, they should understand the importance of having an independent statistical agency that provides trustworthy statistics.

Publishable statistics should be available to the whole community. The media plays a valuable role in disseminating statistics. Most of the public find out about the latest official statistics through media reports, on the electronic media or even the printed media. There also needs to be public understanding and acceptance of the importance of an independent statistical agency (or at least among those of influence). This cannot be taken for granted. The senior staff of the national statistical agency need to keep broadcasting this message. The media can be very helpful in that respect.

\section{Scenarios}

The following are some scenarios that put pressure on the chief statistician to protect the independence of the official statistical agency. For each scenario, I have suggested some actions by the chief statistician. Some may be easier said than done. There is also a bias towards appropriate actions in my own country where there is widespread support for an independent official statistical agency and responding to these testing scenarios is somewhat easier.

The scenarios I discuss are:

1. Political pressures to amend statistics so that they reflect better on the Government (e.g. Greek public debt statistics).

2. Government attempts to intervene in the methods used to compile statistics (e.g. Argentine CPI).

3. Classification of large transactions between the public and private sectors (influencing the size of public debt).

4. Changes in publication date; early release of publications. 
5. Media restrictions.

6. Budget limitations.

In all these scenarios, it is usually prudent to get an opinion from a third party. This can be a former senior statistician from your own country or someone from another country. It can be another present or past public official who has the wisdom and experience to give an informed view. It is also best to try to resolve the issue within your own country initially although that may not always be possible.

Scenario 1: Political pressures to amend statistics so that they reflect better on the Government

- The first step should be to seek independent expert views on the methods and be prepared to make the report publicly available. Ideally the expert should be from another country or the international agency responsible for the methods.

- There should be some attempt to try to convince the Government and other key stakeholders of the implications of amending statistics for non-professional reasons. The independent report mentioned in the previous point should provide some leverage. Often Governments will not be aware of all the implications of their requests and that globalisation means that official statistics are used beyond the country and can influence financial markets to the disadvantage of the country. You should seek support from influential partners in these persuasion activities.

- It is prudent to inform the relevant international agencies of the dilemma if the steps above do not seem to be working.

- You may want to consider involving the media or at least trusted and knowledgeable journalists when the above steps do not seem to be working? For economic statistics, the international media may be interested in the issue. However, this will almost certainly break down any relationship of trust between you and the Government and the next step is a probable consequence.

- Resignation (or the threat to resign) should be a consideration.

Scenario 2: Government attempts to intervene in the methods used to compile statistics

- The first step is to seek independent expert views on the methods and be prepared to make the report publicly available. Ideally the expert should be from another country or the international agency responsible for the methods.
- As for the previous scenario, there should be some attempt to try to convince the Government and other key stakeholders that the methods should not be changed. They should be warned of the implications.

- The relevant international agencies should be advised of the dilemma and their advice/support sought.

- As for Scenario 1, involving the media and resignation (or the threat to resign) might be a consideration.

Scenario 3: Classification of large transactions between the public and private sectors (influencing the size of public debt)

This often arises because governments like to give the impression they are 'smaller' especially in areas like public debt. For some countries, the level of debt can be part of a regulatory requirement. More generally, there can be important political and financial considerations if the debt is seen as large.

- The first step is to ensure you fully understand the transaction - they are often complex. Independent advice may be required to assist you understand the transaction.

- In interpreting the classification, it is essential to refer to the relevant international standard. There may be some useful 'case law' from another country which can be obtained from the international agency.

- It may be prudent to assemble a group of experts to discuss the treatment - not just statisticians as you need some expertise in public finance and government accounting. These experts should not have any political agenda. They should be offering their view based on their professional expertise only - some could come from outside the country.

- It is usually wise to seek advice of the relevant international agency.

- It is important to provide a public explanation of decision.

Scenario 4: Changes in publication date; early release of publications

There may be several reasons for requests for release date changes. Most commonly, the statistical agency cannot make the original publication timetable because of production difficulties. However, the government may request changes sometimes for reasons of political expediency but sometimes for valid reasons.

- There should be a Release Calendar, at least for the major releases. 
- If the statistical agency wishes to change the release date, the reasons need to be explained. Otherwise, there may be speculation on the reasons for the changes which may be incorrect. The explanation should be given soon after the decision to change has been made.

- For economic statistics that may affect financial markets, additional steps should be taken to ensure they are informed of the change and the reasons. The media is generally useful in this respect.

- The above steps should also be applied to government requests for a change where the request is for a valid reason (that would be publicly accepted). For example, the Treasurer (Minister of Finance) asked me if I could release the national accounts one day earlier because he was going to be on a long haul flight on the day of the release and he was expected by the media and financial markets to comment on the national accounts soon after their release. This request was made 2 months before the proposed release date.

- If the Government requests a change for political reasons, it should be refused. This should be done privately in the first instance. If this is not sufficient, it will be necessary to involve others of influence.

- Resignation (or the threat to resign) might be a consideration.

Scenario 5: Restrictions on talking to the media

- A core function of an independent statistical agency is to disseminate statistics. For the majority of the public, they find out about official statistics through the media. This requires a good relationship with media.

- In speaking to media, it is important to focus on statistical facts and explanatory information. Commentary on the success or failure of policy should be avoided at all costs.

- If there are media restrictions, this should be taken up with the Government explaining that media contact by the official statistical agency does not prevent the Government (and others) to put their own interpretation on the statistics.

Scenario 6: Budget limitations

- It is a right of the Government to decide how much to spend on official statistics and to put pressure on agencies to improve the efficiency with which they provide official statistics. This is not really interfering with the independence of official statistical agency unless the budget is decimated to the extent that the official statistical agency cannot really perform its functions.
- It could be regarded as political interference if budget is withdrawn for specific statistics that are not generally regarded as low priority and might reflect on the performance of government.

- The best strategy to avoid very large reductions in budget is to have a strong relationship with key users, including Government users, and provide them with a good service. They are more likely to defend you in this situation and put pressure on government.

\section{Concluding remarks}

Official Statistics provide a mirror on society. They enable the performance of government to be judged, which is especially important for democracies. Trust in official statistics is crucial. This is only really possible with an independent statistical agency that is seen not to be unduly influenced by Government.

The UN General Assembly has endorsed the Fundamental Principles of Official Statistics - this may provide leverage for arguments with Governments (and others) as they provide the fundamental principles for an independent and effective statistical agency.

'Up-to-date, valid and reliable statistics are essential for the management of a democratic society. In preand non-democratic societies information and hence statistics was part of the political power base of the rulers, kings, princes, dictators or colonising powers. The people had no access to statistical information. The democratisation of regimes changed the role of official statistics. They were now considered public goods and were shared with the population and are means of verification of government compliance with policies. Information is power: who owns information owns power." Malaguerra and MacDonald [2].

\section{References}

[1] Laux R. (2013), UK Official Statistics - from new Public Management to Public Value, Proceedings of $59^{\text {th }}$ World Statistics Congress.

[2] Malaguerra C. and MacDonald A. (2016), Statistics as an instrument for prosperous, transparent and democratic societies, Journal of IAOS. 